\title{
Performance of weighted estimating equations for longitudinal binary data with drop-outs missing at random
}

\author{
John S. Preisser ${ }^{1, * \dagger}$, Kurt K. Lohman ${ }^{2}$ and Paul J. Rathouz ${ }^{3}$ \\ ${ }^{1}$ Department of Biostatistics, CB \#7420, School of Public Health, University of North Carolina, \\ Chapel Hill, NC 27599, U.S.A. \\ ${ }^{2}$ Section on Biostatistics, Department of Public Health Sciences, Wake Forest University School of Medicine, \\ Medical Center Boulevard, Winston-Salem, NC 27157, U.S.A. \\ ${ }^{3}$ Department of Health Studies, University of Chicago, 5841 S. Maryland Ave., MC 2007, Chicago, \\ IL 60637, U.S.A.
}

\begin{abstract}
SUMMARY
The generalized estimating equations (GEE) approach is commonly used to model incomplete longitudinal binary data. When drop-outs are missing at random through dependence on observed responses (MAR), GEE may give biased parameter estimates in the model for the marginal means. A weighted estimating equations approach gives consistent estimation under MAR when the drop-out mechanism is correctly specified. In this approach, observations or person-visits are weighted inversely proportional to their probability of being observed. Using a simulation study, we compare the performance of unweighted and weighted GEE in models for time-specific means of a repeated binary response with MAR drop-outs. Weighted GEE resulted in smaller finite sample bias than GEE. However, when the drop-out model was misspecified, weighted GEE sometimes performed worse than GEE. Weighted GEE with observation-level weights gave more efficient estimates than a weighted GEE procedure with cluster-level weights. Copyright (c) 2002 John Wiley \& Sons, Ltd.
\end{abstract}

KEY WORDS: correlated data, drop-outs, estimating equations, logistic models, repeated measures

\section{INTRODUCTION}

In longitudinal studies, subjects often have data missing due to missed visits, commonly when subjects drop-out of a study or are lost to follow-up. A subject is called a drop-out when the response variable is observed through a certain visit and is missing for all subsequent visits [1]. The problem of drop-outs can be particularly acute in epidemiological cohort studies where interest lies in estimating trends over time and where subjects are followed prospectively over

\footnotetext{
* Correspondence to: John S. Preisser, Department of Biostatistics, CB \#7420, School of Public Health, University of North Carolina, Chapel Hill, NC 27599, U.S.A.

† E-mail: jpreisse@bios.unc.edu

Contract/grant sponsor: American Cancer Society; contract/grant number: IRG-198A

Contract/grant sponsor: National Institutes of Health; contract/grant number: AG14131
}

Copyright (c) 2002 John Wiley \& Sons, Ltd.

Received August 1999 Accepted January 2002 
a period spanning several years. The GEE approach [2] has been widely applied in estimating time trends from incomplete longitudinal binary data such as those arising in cohort studies. The performance of GEE for unequal cluster sizes and binary outcomes has been evaluated for between-cluster effects such as found in geographically clustered data [3] and in doseresponse studies in toxicology [4] and teratology [5]. Other simulation studies restrict focus to equal cluster sizes [6-9]. Lipsitz et al. [10] evaluate GEE by simulation for a bivariate binary response when drop-out occurs prior to the second time point. Evaluation by simulation of the GEE method for estimating time trends from repeated binary data with more than two time points in the presence of drop-outs appears missing from the literature.

To address this deficiency, this paper presents a simulation experiment motivated, in part, by an analysis of cigarette smoking trends among young adults in the Coronary Artery Risk Development in Young Adults (CARDIA) study [11]. In that study, more than 5000 black and white males and females were followed for 7 years and the outcome, self-reported cigarette smoking status (yes/no), was recorded on four occasions. About two-thirds of the participants had complete data. The probability of drop-out conditional upon not dropping out at earlier visits was greater for those who were smokers at previous visits than for those who were nonsmokers. In this case, an analysis based upon GEE may give biased estimates of parameters for the regression model of the marginal probabilities describing trends in smoking prevalence. Given the limitations of GEE, there is a growing interest in weighted generalized estimating equations [11-16], which give consistent estimates when the model for the missing data has been correctly specified and consistently estimated.

The validity of an estimating procedure for regression model parameters depends upon model assumptions, including those for missing data. In longitudinal models, the drop-out mechanism may be described hierarchically as data missing completely at random (MCAR), data missing at random, or data missing not at random (MNAR) [17]. The data are MCAR if the drop-out and measurement processes are independent. Under this scenario, the probability of missingness for any response depends in no way on the responses or covariates, whether observed or unobserved. The data are missing at random if missingness depends on observed data but not on unobserved data. In repeated measures studies with drop-outs, and where interest lies in a regression model, two types of missing at random should be delineated. First, covariate dependent missingness allows the missingness of responses to depend only upon covariates. Second, an assumption of missing at random depending upon observed outcomes, which we denote MAR, allows missingness to depend on the observed responses from previous visits as well as observed covariates. Conditional upon these observables, missingness does not depend upon the current or future responses. Finally, missing data is non-ignorable or missing not at random (MNAR) if the missingness is related to the unobserved responses [18]. Neither GEE nor weighted GEE, as considered here, is appropriate in this case. Whether the missingness process is MAR, as opposed to MNAR, often involves assumptions which cannot be tested with the data. Weighted GEEs valid under MNAR [19] are not considered in this paper.

We report on simulation study results that evaluate the performance of GEE and weighted GEE under possible misspecification of models for drop-outs and intraperson correlation. We evaluate bias, test size, coverage of nominal 95 per cent confidence intervals, and relative efficiency under different working correlation structures. Two different formulations of weighted GEE, due to Robins et al. [12] and to Fitzmaurice et al. [13], are studied with data simulated under several different missingness mechanisms. 


\section{WEIGHTED ESTIMATING EQUATIONS FOR LONGITUDINAL DATA}

We consider marginal models for longitudinal studies that relate the expected value of an individual's binary response at time $t$ (for example, the probability of being a smoker at time $t$ ) to covariates via a known link function $g(\cdot)$ [20]. Assume a set of $T$ observation times common to all individuals, and define the complete data response vector $Y_{i}=\left(Y_{i 1}, \ldots, Y_{i T}\right)^{\prime}$ for individual $i, i=1, \ldots, K$. For example, if a subject possesses the outcome of interest (subject is a smoker) $Y_{i t}=1$, and $Y_{i t}=0$ if the subject does not possess this characteristic (subject is not a smoker). The corresponding complete covariate matrix for individual $i$ is $X_{i}=\left(X_{i 1}, \ldots, X_{i T}\right)^{\prime}$ where $X_{i t}$ is a $p \times 1$ covariate vector at time $t$.

Now suppose individual $i$ is observed at times $t=1, \ldots, T_{i}$, giving the $T_{i} \times 1$ vector of observed responses, $Y_{i}^{o}=\left(Y_{i 1}, \ldots, Y_{i T_{i}}\right)^{\prime}, 1 \leqslant T_{i} \leqslant T$. Likewise, let $X_{i}^{o}=\left(X_{i 1}, \ldots, X_{i T_{i}}\right)^{\prime}$ represent the corresponding matrix of covariates. Next, let $E\left(Y_{i t} \mid X_{i}\right)=\pi_{i t}$ be the probability that $Y_{i t}=1$ given $X_{i}$, and let $\pi_{i}=\left(\pi_{i 1}, \ldots, \pi_{i T}\right)^{\prime}$ and $\pi_{i}^{o}=\left(\pi_{i 1}, \ldots, \pi_{i T_{i}}\right)^{\prime}$. Our goal is to make inferences about marginal probabilities, $\pi_{i t}(\beta)$, where $g\left(\pi_{i t}\right)=X_{i t}^{\prime} \beta$, for individuals regardless of whether or not they drop out. In particular, our interest is in generalized linear models for $\pi_{i t}$ given by the logit link function, $g\left(\pi_{i t}\right)=\ln \left[\pi_{i t} /\left(1-\pi_{i t}\right)\right]$.

To estimate $\beta$, while accounting for correlation among an individual's repeated responses, Liang and Zeger [2] proposed generalized estimating equations

$$
\sum_{i=1}^{K} D_{i}^{o^{\prime}}\left(X_{i}^{o}, \beta\right)\left(V_{i}^{o}\right)^{-1}\left[Y_{i}^{o}-\pi_{i}^{o}(\beta)\right]=0
$$

where $D_{i}^{o}\left(X_{i}^{o}, \beta\right)=\partial \pi_{i}^{o} / \partial \beta$ is a $T_{i} \times p$ matrix and $V_{i}^{o}$ is a working covariance matrix for $Y_{i}^{o}$. A working model for the correlation is assumed such that $V_{i}^{o}=A_{i}^{o} C_{i}^{o} A_{i}^{o}, A_{i}^{o}=\operatorname{diag}\left\{v_{i t}^{1 / 2}\right\}$ is a $T_{i} \times T_{i}$ diagonal matrix where $v_{i t}=\pi_{i t}\left(1-\pi_{i t}\right)$ for binary data, and $C_{i}^{o}(\rho)$ is a working correlation matrix that depends on an unknown nuisance parameter vector $\rho$. Equation (1) yields a consistent estimate of $\beta$ if the data are MCAR or missingness depending only on the vector of covariates, whereas, under MAR, a GEE analysis may give biased estimates.

An alternative estimating equations approach that can provide unbiased inference in longitudinal studies with drop-outs has been proposed by Robins et al. [12]. They proposed a class of estimating equations in which observations or person-visits have weights inversely proportional to their probability of being observed. This weighted generalized estimating equations approach, which has been called the inverse probability of censoring weighted GEE estimator, is valid under an MAR assumption even if the correlation model is misspecified, provided the model for estimating the probability for missing response is correctly specified. A consistent estimate of $\beta$ may be obtained from

$$
\sum_{i=1}^{K} D_{i}^{\prime}\left(X_{i}, \beta\right) V_{i}^{-1} W_{i}\left[Y_{i}-\pi_{i}(\beta)\right]=0
$$

where $D_{i}\left(X_{i}, \beta\right)=\partial \pi_{i} / \partial \beta$ and $V_{i}=A_{i} C_{i} A_{i}$ is a $T \times T$ working covariate matrix for $Y_{i}$. Here, the drop-out process is taken into account through specification of a $T \times T$ diagonal matrix of occasion-specific weights, $W_{i}=\operatorname{diag}\left\{R_{i 1} w_{i 1}, \ldots, R_{i T} w_{i T}\right\}$, where $R_{i t}=1$ if the $i$ th individual's response is observed at time $t$, and 0 otherwise. In other words, the weight is given by $w_{i t}$ for observed visits and 0 for unobserved visits. The definition and estimation of $w_{i t}$, the inverse 
of the probability that the $i$ th individual is observed at the $t$ th visit, is described below. Note that unless $C_{i}=I$, (2) depends upon covariates, assumed known, from both observed and unobserved occasions. The choice of the working correlation matrix in (2) affects efficiency [14]. Like GEE, the use of sandwich variance estimators in weighted GEE provides robustness, in an asymptotic sense, to misspecification of the correlation structure. With consistent estimation of weights provided by a correctly specified drop-out model, weighted GEE does not require correct specification of the correlation structure in order to estimate $\beta$ and the variance of its estimate consistently.

To characterize the missing data process and obtain estimates $\hat{w}_{i t}$, let $\lambda_{i t}=P\left(R_{i t}=1 \mid R_{i(t-1)}\right.$ $\left.=1, X_{i}, Y_{i}, \alpha\right)$ denote the probability of observing a response at time $t$ for the $i$ th individual conditional on the individual being observed at the time $t-1$. Following the convention of Robins et al. [12], we do not consider intermittent missing data patterns, that is, $\left(R_{i t}=0, R_{i(t+k)}=1\right.$, for $k>0$ is not allowed). For the first time point, assume $R_{i 1}=1$ and define $\lambda_{i 1}=1$. The MAR assumption of the weighted GEE approach specifies that $\lambda_{i t}=P\left(R_{i t}=1 \mid R_{i(t-1)}=1, X_{i}\right.$, $\left.\left(Y_{i 1}, \ldots, Y_{i(t-1)}\right), \alpha\right)$, so that conditional upon the past responses $Y_{i 1}, \ldots, Y_{i(t-1)}, R_{i t}$ and $Y_{i t}$ are independent. The missing data mechanism therefore depends only on observed data and may be specified up to a $q \times 1$ vector of unknown parameters, $\alpha$. We obtain $\hat{\lambda}_{i t}$ by fitting a logistic model, $\operatorname{logit}\left\{\lambda_{i t}(\alpha)\right\}=Z_{i t} \alpha$, with a vector of predictors, $Z_{i t}$ which may include visit indicator variables, covariates and past responses. The log partial likelihood for the $i$ th subject is

$$
\sum_{t} R_{i, t-1} \log \left\{\lambda_{i t}(\alpha)^{R_{i t}}\left[1-\lambda_{i t}(\alpha)\right]^{1-R_{i t}}\right\}
$$

Differentiation with respect to $\alpha$ yields $S_{i}(\alpha)=\sum_{t} R_{i, t-1} Z_{i t}\left[R_{i t}-\lambda_{i t}(\alpha)\right]$, the score component of the $i$ th individual. The partial likelihood estimate $\hat{\alpha}$ and thus $\hat{\lambda}_{i t}$ 's are obtained by solving the estimating equations $\sum_{i} S_{i}(\alpha)=0$. The weight $w_{i t}$ for the $i$ th individual at the $t$ th time is the inverse of the unconditional probability of being observed at time $t$, estimated as the inverse of the cumulative product of conditional probabilities, $\hat{w}_{i t}^{-1}=\hat{\lambda}_{i 1} \times \cdots \times \hat{\lambda}_{i t}$. Note that an observation with a low probability of being observed will receive a large weight.

The weighted GEE estimate is obtained by solving (2) where $W_{i}(\hat{\alpha})$ is a diagonal matrix with elements $\hat{w}_{i t}$, for $t=2, \ldots, T_{i}$, and $\hat{w}_{i 1}=1$. As in GEE, iteratively reweighted estimation of $\beta$ alternates at each step with method of moments estimation of $\rho$. Under correctly specified models for the marginal means and for the drop-out process, equation (2) yields a consistent estimate of $\beta$ which has an asymptotic normal distribution with consistent estimator of its asymptotic variance given by

$$
\left(\sum_{i=1}^{K} D_{i}^{\prime} V_{i}^{-1} W_{i} D_{i}\right)^{-T} \sum_{i=1}^{K} E_{i} E_{i}^{\prime}\left(\sum_{i=1}^{K} D_{i}^{\prime} V_{i}^{-1} W_{i} D_{i}\right)^{-1}
$$

where $E_{i}=U_{i}-\left(\sum_{i=1}^{K} U_{i} S_{i}^{\prime}\right)\left(\sum_{i=1}^{k} S_{i} S_{i}^{\prime}\right) S_{i}, U_{i}=D_{i}^{\prime} V_{i}^{-1} W_{i}\left(Y_{i}-\pi_{i}\right)$, and $S_{i}$ is the score component for the $i$ th individual from the drop-out model [12]. Note that $\sum_{i=1}^{K} E_{i} E_{i}^{\prime}$ is the matrix sum of squares and cross-products of the residuals from the multivariate regression of the score component from (2) on the score vectors from the drop-out model (3). The use of $\sum_{i=1}^{K} E_{i} E_{i}^{\prime}$ in the centre of (4) instead of $\sum_{i=1}^{K} U_{i} U_{i}^{\prime}$ adjusts for estimation of $\alpha$. 
Fitzmaurice et al. [13] studied a weighted GEE using cluster level weights. Their weighted estimating equations are

$$
\sum_{i=1}^{K} w_{i} D_{i}^{o^{\prime}}\left(X_{i}^{o}, \beta\right)\left(V_{i}^{o}\right)^{-1}\left[Y_{i}^{o}-\pi_{i}^{o}(\beta)\right]=0
$$

with cluster-level (subject-specific) weights, $w_{i}$. An individual's weight is the inverse of the probability of dropping out at the observed time of drop-out. Letting $m$ denote the time of drop-out, $2 \leqslant m \leqslant T+1$, for the $i$ th individual

$$
w_{i}^{-1}=\left(\prod_{t=2}^{m-1} \lambda_{i t}\right)\left(1-\lambda_{i m}\right)^{I\{m \leqslant T\}}
$$

where $I(\cdot)$ is the indicator function. Again, following Robins et al. [12], a consistent estimator for the variance of $\hat{\beta}$ is

$$
\left(\sum_{i=1}^{K} w_{i} D_{i}^{o^{\prime}}\left(V_{i}^{o}\right)^{-1} D_{i}^{o}\right)^{-T} \sum_{i=1}^{K} E_{i}^{o} E_{i}^{o^{\prime}}\left(\sum_{i=1}^{K} w_{i} D_{i}^{o^{\prime}}\left(V_{i}^{o}\right)^{-1} D_{i}^{o}\right)^{-1}
$$

where $E_{i}^{o}=U_{i}^{o}-\left(\sum_{i=1}^{K} U_{i}^{o} S_{i}^{\prime}\right)\left(\sum_{i=1}^{k} S_{i} S_{i}^{\prime}\right) S_{i}$ and $U_{i}^{o}=w_{i} D_{i}^{o^{\prime}}\left(V_{i}^{o}\right)^{-1}\left(Y_{i}^{o}-\pi_{i}^{o}\right)$.

\section{A SIMULATION STUDY}

\subsection{Design}

A simulation experiment was performed to compare six methods of analysis under different conditions pertaining to the correlation structure, the missing data mechanism and the amount of missingness. The methods include GEE, given by (1), and the two weighted GEE methods, (2) and (5), respectively, each under independence and exchangeable working correlation structures. The design of the simulation study was based partly upon characteristics of data from the CARDIA study where the binary response was self-described smoking status at time $t$. For each individual, a vector of correlated binary responses, $Y_{i}=\left(Y_{i 1}, Y_{i 2}, \ldots, Y_{i T}\right)$, indicating smoking status at $T$ time points were generated, where the marginal log-odds of being a smoker at time $t=1,2, \ldots, T$ was taken to be $\operatorname{logit}\left[P\left(Y_{i t}=1\right)\right]=\beta_{1}+\beta_{T}\left(\frac{t-1}{T-1}\right)$. Throughout, we fixed $\beta_{1}=-0.7$ and $\beta_{T}=0.2$ corresponding to marginal probabilities $\pi_{i 1}=0.332$ and $\pi_{i T}=0.378$ indicating a moderate increase in smoking prevalence. Correlated binary responses were generated using a method based upon a family of multivariate binary distributions with a certain conditional linear property. This method requires specification of the $T \times 1$ vector of marginal means $\pi_{i}$, and the $T \times T$ correlation matrix, $C_{i}$. See the Appendix for a detailed description of the data generating process.

Data were generated under three correlation structures: independence given by $C_{i}=I$, and exchangeable correlation structures with the common correlation among any two time points taking values of $\rho=0.2$ and $\rho=0.6$. These three correlation structures represent no correlation, weak correlation and strong correlation, respectively. The strong correlation case resembles data from the CARDIA study where pairwise correlations are high irrespective of the time between measures because there were relatively few young adults who initiated or quit smoking 
over the course of the study. Each method was applied with $K=50, K=100$ and $K=200$ subjects. We set $T=6$ for the first two cases, and $T=4$ when $K=200$.

Observed data, $Y_{i}^{o}$, were generated according to simulated patterns of missingness given by the indicators $R_{i 2}, \ldots, R_{i T}$ generated under various models for the drop-out process. We assumed that $R_{i 1}=1$ with probability 1 and set $R_{i, t+k}=0, k>0$ whenever $R_{i t}=0$ so that intermittent missing data patterns are not allowed. Missingness models are of the form

$$
\operatorname{logit}\left(\lambda_{i t}\right)=\alpha_{0}+\alpha_{1} y_{i(t-1)}^{\star}+\alpha_{2} y_{i(t-2)}^{\star} I(t>2)+\alpha_{3} y_{i t}^{\star} \quad t=2, \ldots, T
$$

where $I(t>2)=1$ if $t>2$, and 0 otherwise, and $y_{i t}^{\star}=2 y_{i t}-1$ ( $y_{i t}$ is a realization of the random variable $Y_{i t}$ ) giving $y_{i t}^{\star}=1$ if the $i$ th individual was a smoker at time $t$ and -1 if a non-smoker. Model (7) specifies that $\lambda_{i t}$, the probability of being observed at time $t$, given being observed at time $t-1$, may depend on the smoking status at the current or previous two observations. Indicators for non-missingness, $R_{i 2}, \ldots, R_{i T}$, were generated from five different general models for drop-out determined by $\alpha=\left(\alpha_{0}, \alpha_{1}, \alpha_{2}, \alpha_{3}\right)$. The five missing data mechanisms are given by (i) $\alpha=\left(\alpha_{0}, 0,0,0\right)$, (ii) $\alpha=\left(\alpha_{0},-0.2,0,0\right)$, (iii) $\alpha=\left(\alpha_{0},-0.5,0,0\right)$, (iv) $\alpha=\left(\alpha_{0},-0.5,-0.2,0\right)$, and (v) $\alpha=\left(\alpha_{0}, 0,0,-0.5\right)$. Case (i) is an MCAR process, cases (ii) and (iii) are MAR (weak and strong, respectively), case (iv) is a more complicated MAR process (which we call twodependent) where drop-out depends upon smoking status at the two previous time points. Finally, case (v) is MNAR since drop-out depends upon the potentially unobserved value of smoking at the current time point. These simulations were repeated by considering four different levels of $\alpha_{0}$, a parameter that roughly speaking relates to the average conditional probability of drop-out under any given model (7). We consider values of 3.0, 2.2, 1.4 and 0.4 for $\alpha_{0}$. These four values specify the 'average' probability of drop-out at the current visit given not having dropped out prior to the visit to be 0.05 ('minimal'), 0.10 ('mild'), 0.20 ('moderate') and 0.40 ('severe'), respectively. For $K=50$ we do not report severe drop-out since resulting data contains too little information to justify use of the methods considered here, and for $K=100$ or $K=200$ we do not consider minimal drop-out since preliminary investigation found the results were similar to the case of mild drop-out.

For each of the 45 ways that data were generated (three correlation values $\times$ five general missing data models $\times$ three overall magnitudes of missingness per scenario), we compared the six methods of analysis using 1000 replicate observations. For weighted GEE, we used an estimated missing data model like (7) but that included only an intercept and smoking status at the previous visit (that is, $\alpha_{2}=\alpha_{3}=0$ ). Thus, the first three cases of the missingness generating process above would expect to yield approximately unbiased weighted GEE estimates of $\beta$, while the two-dependent MAR and the MNAR process would correspond to misspecified drop-out models. The parameter of interest is $\beta_{T}$, the change in the log-odds of smoking from the last compared to the first time point. We fitted the unconstrained (if overparameterized) marginal log-odds model, $\operatorname{logit}\left[P\left(Y_{i t}=1\right)\right]=\beta_{1}+\beta_{t} I(t>1), t=1, \ldots, T$, estimating $T$ regression parameters instead of 2 . None the less, $\beta_{T}$ in the fitted model retains the same interpretation as in the model which generated the data. We specified binomial-type variances, $\operatorname{var}\left(Y_{i t}\right)=\pi_{i t}\left(1-\pi_{i t}\right)$, and used Liang and Zeger's [2] all-available-pairs estimator to estimate $\rho$.

For each of the six methods of analysis, we evaluate, for $\beta_{T}$, per cent relative bias, test size, observed coverage of a nominal 95 per cent confidence interval, and the accuracy of its variance estimator. Per cent relative bias was computed as $(1 / 1000) \sum_{s=1}^{1000}\left(\hat{\beta}_{s}-\beta_{T}\right) / \beta_{T} \times 100$ 
per cent where $\beta_{T}=0.2$ and $\hat{\beta}_{s}$ is the estimate of $\beta_{T}$ from the $s$ th simulated replicate. Test size was defined as the proportion of times $\left|\hat{\beta}_{T} / \operatorname{SE}\left(\hat{\beta}_{T}\right)\right| \geqslant t_{0.975, K-T}$ when $\beta_{T}=0$, where $t_{0.975, K-T}$ is the 97.5th percentile of Student's $t$-distribution with $K-T$ degrees of freedom, and 'SE' denotes the empirical sandwich standard error for GEE or the standard error from (4) or (6) for the respective weighted GEE methods. Coverage was defined as the per cent of 95 per cent Wald-type confidence intervals for $\beta_{T}$ using the same standard error formulae as for size that contained $\beta_{T}=0.2$. Finally, the standard errors for the six methods are evaluated by comparing their average values over all simulations to the Monte Carlo or empirical standard deviation of the $1000 \hat{\beta}_{T}$ parameter estimates.

In addition to examining the four criteria described above, the efficiency of the GEE and weighted GEE estimators relative to a maximum likelihood estimator was determined for $\beta_{4}$ when $K=200$. The relative efficiency was defined as the ratio of the Monte Carlo mean squared error of the maximum likelihood estimator $\hat{\beta}_{4, \mathrm{ML}}$, to that of estimating equations estimator, $\hat{\beta}_{4}$. Our rationale for examining a maximum likelihood estimator is that the weighted GEE estimators given by (2) and (5) are not in general the semi-parametric efficient estimators in their classes. We consider the maximum likelihood estimator $\hat{\beta}_{4, \mathrm{ML}}$ based upon the unconstrained multinomial likelihood model for the $2^{4}$ contingency table formed by the crossclassification of the binary smoking outcomes from the four time points. This model places no restrictions on the $16 \times 1$ vector of joint cell probabilities, $\theta$, other than that its elements sum to 1 . Thus, the 'working' model for maximum likelihood estimation is not the same as the data generation model which it has as a special case. The 'working' model for maximum likelihood coincides with working models used in the GEE and weighted GEE methods with respect to the marginal mean structure. However, unlike the estimating equations methods considered, its implicit working covariance structure is unstructured since no constraints are placed on the joint probabilities. For $T=4, \hat{\beta}_{T, \mathrm{ML}}$ is easily determined as a matrix function of $\hat{\theta}$, the maximum likelihood estimator of $\theta$. In particular, $\hat{\beta}_{4, \mathrm{ML}}=A_{3} \log A_{2} \hat{\theta}$ with $A_{2}$ a matrix of 0's and 1's transforming the joint cell probabilities to the marginal probabilities, the log operator defined elementwise, and $A_{3}$ a constrast vector of -1 's, 0 's and 1's. Finally, under the unconstrained multinomial model, $\hat{\theta}$ has a closed-form expression based upon factored likelihoods for multinomial data with monotone patterns of missingness (Little and Rubin, reference [17], Section 9.2). When there is complete data (that is, $T_{i}=T$ for $i=1, \ldots, K$ ), $\hat{\theta}$ is simply the vector of observed cell relative frequencies.

\subsection{Results}

The results of the simulation study are given in the tables where 'WEE' refers to the observation-weighted GEE procedure using (2) and 'CWEE' refers to the cluster-weighted GEE procedure using (5). Results for the WEE method with independent working correlation matrix (WEE-indep) are not shown in the tables since these results were nearly the same as the results for WEE with exchangeable working correlation (WEE-exch). We comment with a footnote in a table whenever WEE-indep gives a different result than WEE-exch.

Tables I to III report on bias of $\hat{\beta}_{T}$ for $K=50, K=100$ and $K=200$, respectively. In each table, all methods have large bias under MNAR as expected. We consider per cent relative bias to be low if it is at most 25 per cent, and to be large otherwise. Then, under those cases where the asymptotic bias is zero, that is all methods under MCAR missingness, 
Table I. Per cent relative bias of $\hat{\beta}_{6}, K=50, T=6$.

\begin{tabular}{|c|c|c|c|c|c|c|c|}
\hline \multirow[t]{3}{*}{$\rho$} & \multirow{2}{*}{\multicolumn{2}{|c|}{$\begin{array}{c}\text { True model } \\
\text { Drop-out }\end{array}$}} & \multicolumn{5}{|c|}{ Working model } \\
\hline & & & \multicolumn{2}{|c|}{ GEE } & \multirow{2}{*}{$\frac{\text { WEE }}{\text { Exch }}$} & \multicolumn{2}{|c|}{ CWEE } \\
\hline & Type & Amount & Indep & Exch & & Indep & Exch \\
\hline 0.0 & $\begin{array}{l}\text { MCAR } \\
\text { MAR-weak } \\
\text { MAR-strong } \\
\text { MAR-2-dep } \\
\text { MNAR }\end{array}$ & $5 \%$ & $\begin{array}{r}-8 \\
-4 \\
7 \\
9 \\
-21\end{array}$ & $\begin{array}{r}-8 \\
-4 \\
6 \\
10 \\
-21\end{array}$ & $\begin{array}{r}-8 \\
-4 \\
7 \\
9 \\
-21\end{array}$ & $\begin{array}{l}26 \\
15 \\
40 \\
12 \\
26\end{array}$ & $\begin{array}{r}30 \\
7 \\
13 \\
-14 \\
27\end{array}$ \\
\hline 0.2 & $\begin{array}{l}\text { MCAR } \\
\text { MAR-weak } \\
\text { MAR-strong } \\
\text { MAR-2-dep } \\
\text { MNAR }\end{array}$ & & $\begin{array}{r}6 \\
-5 \\
-32 \\
-29 \\
-43\end{array}$ & $\begin{array}{r}5 \\
4 \\
-9 \\
0 \\
-33\end{array}$ & $\begin{array}{r}6 \\
5 \\
-9 \\
-4 \\
-38\end{array}$ & $\begin{array}{r}22 \\
42 \\
15 \\
-19 \\
-80\end{array}$ & $\begin{array}{r}18 \\
23 \\
-2 \\
-19 \\
-75\end{array}$ \\
\hline 0.6 & $\begin{array}{l}\text { MCAR } \\
\text { MAR-weak } \\
\text { MAR-strong } \\
\text { MAR-2-dep } \\
\text { MNAR }\end{array}$ & & $\begin{array}{r}0 \\
-29 \\
-70 \\
-97 \\
-83\end{array}$ & $\begin{array}{r}0 \\
-3 \\
2 \\
-3 \\
-29\end{array}$ & $\begin{array}{r}-0 \\
-2 \\
5 \\
-12 \\
-41\end{array}$ & $\begin{array}{r}17 \\
19 \\
8 \\
-49 \\
-90\end{array}$ & $\begin{array}{r}-0 \\
3 \\
3 \\
-11 \\
-62\end{array}$ \\
\hline 0.0 & $\begin{array}{l}\text { MCAR } \\
\text { MAR-weak } \\
\text { MAR-strong } \\
\text { MAR-2-dep } \\
\text { MNAR }\end{array}$ & $10 \%$ & $\begin{array}{r}-10 \\
-7 \\
7 \\
6 \\
-55\end{array}$ & $\begin{array}{r}-10 \\
-8 \\
6 \\
6 \\
-55\end{array}$ & $\begin{array}{r}-10 \\
-7 \\
8 \\
5 \\
-55\end{array}$ & $\begin{array}{r}1 \\
3 \\
16 \\
-7 \\
-38\end{array}$ & $\begin{array}{r}-5 \\
-7 \\
-2 \\
-35 \\
-35\end{array}$ \\
\hline 0.2 & $\begin{array}{l}\text { MCAR } \\
\text { MAR-weak } \\
\text { MAR-strong } \\
\text { MAR-2-dep } \\
\text { MNAR }\end{array}$ & & $\begin{array}{l}-1 \\
-17 \\
-61 \\
-64 \\
-94\end{array}$ & $\begin{array}{r}-2 \\
2 \\
-13 \\
-3 \\
-72\end{array}$ & $\begin{array}{r}-1 \\
3 \\
-12 \\
-14 \\
-83\end{array}$ & $\begin{array}{r}1 \\
14 \\
-6 \\
-38 \\
-123\end{array}$ & $\begin{array}{r}2 \\
10 \\
-12 \\
-25 \\
-108\end{array}$ \\
\hline 0.6 & $\begin{array}{l}\text { MCAR } \\
\text { MAR-weak } \\
\text { MAR-strong } \\
\text { MAR-2-dep } \\
\text { MNAR }\end{array}$ & & $\begin{array}{r}-3 \\
-64 \\
-149 \\
-203 \\
-175\end{array}$ & $\begin{array}{r}-5 \\
-5 \\
-5 \\
-16 \\
-63\end{array}$ & $\begin{array}{r}-5 \\
-3 \\
1 \\
-34 \\
-88\end{array}$ & $\begin{array}{r}-2 \\
4 \\
5 \\
-59 \\
-136\end{array}$ & $\begin{array}{r}-5 \\
2 \\
3 \\
-12 \\
-87\end{array}$ \\
\hline 0.0 & $\begin{array}{l}\text { MCAR } \\
\text { MAR-weak } \\
\text { MAR-strong } \\
\text { MAR-2-dep } \\
\text { MNAR }\end{array}$ & $20 \%$ & $\begin{array}{r}-30 \\
-30 \\
3 \\
-9 \\
-110\end{array}$ & $\begin{array}{r}-31 \\
-30 \\
1 \\
-8 \\
-109\end{array}$ & $\begin{array}{r}-29 \\
-31 \\
5 \\
-12 \\
-111\end{array}$ & $\begin{array}{r}-28 \\
-31 \\
9 \\
-2 \\
-107\end{array}$ & $\begin{array}{r}-32 \\
-39 \\
-5 \\
-23 \\
-107\end{array}$ \\
\hline 0.2 & $\begin{array}{l}\text { MCAR } \\
\text { MAR-weak } \\
\text { MAR-strong } \\
\text { MAR-2-dep } \\
\text { MNAR }\end{array}$ & & $\begin{array}{r}-12 \\
-49 \\
-124 \\
-129 \\
-191\end{array}$ & $\begin{array}{r}-15 \\
-8 \\
-32 \\
-17 \\
-154\end{array}$ & $\begin{array}{r}-13 \\
-9 \\
-33 \\
-41 \\
-174\end{array}$ & $\begin{array}{r}-11 \\
-8 \\
-25 \\
-39 \\
-191\end{array}$ & $\begin{array}{r}-13 \\
-5 \\
-26 \\
-7 \\
-171\end{array}$ \\
\hline 0.6 & $\begin{array}{l}\text { MCAR } \\
\text { MAR-weak } \\
\text { MAR-strong } \\
\text { MAR-2-dep } \\
\text { MNAR }\end{array}$ & & $\begin{array}{r}-9 \\
-136 \\
-299 \\
-392 \\
-349\end{array}$ & $\begin{array}{r}-9 \\
-15 \\
-35 \\
-53 \\
-141\end{array}$ & $\begin{array}{r}-10 \\
-17 \\
-22 \\
-110 \\
-195\end{array}$ & $\begin{array}{r}-12 \\
-13 \\
-17 \\
-116 \\
-215\end{array}$ & $\begin{array}{r}-7 \\
-3 \\
-2 \\
-18 \\
-133\end{array}$ \\
\hline
\end{tabular}

WEE-indep per cent relative bias is the same as the reported WEE-exch per cent relative bias rounded to nearest whole per cent. 
Table II. Per cent relative bias of $\hat{\beta}_{6}, K=100, T=6$.

\begin{tabular}{|c|c|c|c|c|c|c|c|}
\hline \multirow[t]{3}{*}{$\rho$} & \multirow{2}{*}{\multicolumn{2}{|c|}{$\begin{array}{c}\text { True model } \\
\text { Drop-out }\end{array}$}} & \multicolumn{5}{|c|}{ Working model } \\
\hline & & & \multicolumn{2}{|c|}{ GEE } & \multirow{2}{*}{$\frac{\text { WEE }}{\text { Exch }}$} & \multicolumn{2}{|c|}{ CWEE } \\
\hline & Type & Amount & Indep & Exch & & Indep & Exch \\
\hline 0.0 & $\begin{array}{l}\text { MCAR } \\
\text { MAR-weak } \\
\text { MAR-strong } \\
\text { MAR-2-dep } \\
\text { MNAR }\end{array}$ & $10 \%$ & $\begin{array}{r}-12 \\
-4 \\
-4 \\
1 \\
-47\end{array}$ & $\begin{array}{r}-12 \\
-4 \\
-4 \\
2 \\
-47\end{array}$ & $\begin{array}{r}-12 \\
-4 \\
-3 \\
2 \\
-47\end{array}$ & $\begin{array}{r}-9 \\
1 \\
-3 \\
-13 \\
-34\end{array}$ & $\begin{array}{r}-12 \\
-4 \\
-12 \\
-34 \\
-30\end{array}$ \\
\hline 0.2 & $\begin{array}{l}\text { MCAR } \\
\text { MAR-weak } \\
\text { MAR-strong } \\
\text { MAR-2-dep } \\
\text { MNAR }\end{array}$ & & $\begin{array}{r}-2 \\
-20 \\
-55 \\
-67 \\
-97\end{array}$ & $\begin{array}{r}-3 \\
-1 \\
-6 \\
-7 \\
-77\end{array}$ & $\begin{array}{r}-2 \\
1 \\
-4 \\
-17 \\
-86\end{array}$ & $\begin{array}{r}0 \\
5 \\
2 \\
-40 \\
-124\end{array}$ & $\begin{array}{r}-2 \\
2 \\
0 \\
-20 \\
-107\end{array}$ \\
\hline 0.6 & $\begin{array}{l}\text { MCAR } \\
\text { MAR-weak } \\
\text { MAR-strong } \\
\text { MAR-2-dep } \\
\text { MNAR }\end{array}$ & & $\begin{array}{r}-1 \\
-60 \\
-150 \\
-199 \\
-172\end{array}$ & $\begin{array}{r}-3 \\
-3 \\
-8 \\
-14 \\
-61\end{array}$ & $\begin{array}{r}-2 \\
-0 \\
-2 \\
-30 \\
-85\end{array}$ & $\begin{array}{r}1 \\
2 \\
-1 \\
-59 \\
-134\end{array}$ & $\begin{array}{r}-1 \\
-1 \\
-0 \\
-9 \\
-84\end{array}$ \\
\hline 0.0 & $\begin{array}{l}\text { MCAR } \\
\text { MAR-weak } \\
\text { MAR-strong } \\
\text { MAR-2-dep } \\
\text { MNAR }\end{array}$ & $20 \%$ & $\begin{array}{r}-24 \\
-17 \\
-2 \\
-3 \\
-97\end{array}$ & $\begin{array}{r}-25 \\
-18 \\
-2 \\
-2 \\
-97\end{array}$ & $\begin{array}{r}-24 \\
-18 \\
-0 \\
-3 \\
-97\end{array}$ & $\begin{array}{r}-24 \\
-17 \\
0 \\
3 \\
-94\end{array}$ & $\begin{array}{r}-26 \\
-19 \\
-5 \\
-10 \\
-94\end{array}$ \\
\hline 0.2 & $\begin{array}{l}\text { MCAR } \\
\text { MAR-weak } \\
\text { MAR-strong } \\
\text { MAR-2-dep } \\
\text { MNAR }\end{array}$ & & $\begin{array}{r}-7 \\
-43 \\
-107 \\
-121 \\
-182\end{array}$ & $\begin{array}{r}-10 \\
-3 \\
-15 \\
-12 \\
-148\end{array}$ & $\begin{array}{r}-7 \\
-1 \\
-12 \\
-31 \\
-164\end{array}$ & $\begin{array}{r}-6 \\
-0 \\
-9 \\
-31 \\
-181\end{array}$ & $\begin{array}{r}-8 \\
0 \\
-8 \\
1 \\
-161\end{array}$ \\
\hline 0.6 & $\begin{array}{l}\text { MCAR } \\
\text { MAR-weak } \\
\text { MAR-strong } \\
\text { MAR-2-dep } \\
\text { MNAR }\end{array}$ & & $\begin{array}{r}-7 \\
-123 \\
-294 \\
-369 \\
-345\end{array}$ & $\begin{array}{r}-7 \\
-8 \\
-31 \\
-40 \\
-133\end{array}$ & $\begin{array}{r}-7 \\
-3 \\
-12 \\
-77 \\
-183\end{array}$ & $\begin{array}{r}-9 \\
-0 \\
-10 \\
-88 \\
-206\end{array}$ & $\begin{array}{r}-6 \\
-0 \\
-2 \\
-4 \\
-128\end{array}$ \\
\hline 0.0 & $\begin{array}{l}\text { MCAR } \\
\text { MAR-weak } \\
\text { MAR-strong } \\
\text { MAR-2-dep } \\
\text { MNAR }\end{array}$ & $40 \%$ & $\begin{array}{r}21 \\
-7 \\
-4 \\
-12 \\
-187\end{array}$ & $\begin{array}{r}15 \\
-11 \\
-9 \\
-11 \\
-191\end{array}$ & $\begin{array}{r}22 \\
-13 \\
-10 \\
-17 \\
-187\end{array}$ & $\begin{array}{r}26 \\
-10 \\
-4 \\
20 \\
-185\end{array}$ & $\begin{array}{r}21 \\
-19 \\
-20 \\
-4 \\
-193\end{array}$ \\
\hline 0.2 & $\begin{array}{l}\text { MCAR } \\
\text { MAR-weak } \\
\text { MAR-strong } \\
\text { MAR-2-dep } \\
\text { MNAR }\end{array}$ & & $\begin{array}{r}-7 \\
-54 \\
-188 \\
-231 \\
-324\end{array}$ & $\begin{array}{r}-31 \\
-10 \\
-57 \\
-58 \\
-315\end{array}$ & $\begin{array}{r}-9 \\
16 \\
-37 \\
-103 \\
-296\end{array}$ & $\begin{array}{r}-5 \\
22 \\
-30 \\
-68 \\
-281\end{array}$ & $\begin{array}{r}-24 \\
6 \\
-37 \\
-33 \\
-286\end{array}$ \\
\hline 0.6 & $\begin{array}{l}\text { MCAR } \\
\text { MAR-weak } \\
\text { MAR-strong } \\
\text { MAR-2-dep } \\
\text { MNAR }\end{array}$ & & $\begin{array}{r}6 \\
-219 \\
-466 \\
-577 \\
-556\end{array}$ & $\begin{array}{r}-46 \\
-58 \\
-109 \\
-144 \\
-330\end{array}$ & $\begin{array}{r}-9 \\
-10 \\
-64 \\
-238 \\
-315\end{array}$ & $\begin{array}{r}-9 \\
-2 \\
-39 \\
-197 \\
-283\end{array}$ & $\begin{array}{r}-40 \\
-23 \\
-33 \\
-65 \\
-255\end{array}$ \\
\hline
\end{tabular}

WEE-indep per cent relative bias is the same as the reported WEE-exch per cent relative bias rounded to nearest whole per cent except for three cases for 40 per cent drop-out: (i) $(\rho=0$, MAR-weak $)=-14$; (ii) $(\rho=0.6$, MAR-strong $)=-66$; (iii) $(\rho=0.6$, MNAR $)=-314$. 
Table III. Per cent relative bias of $\hat{\beta}_{4}, K=200, T=4$.

\begin{tabular}{|c|c|c|c|c|c|c|c|c|}
\hline \multirow[t]{3}{*}{$\rho$} & \multirow{2}{*}{\multicolumn{2}{|c|}{$\begin{array}{c}\text { True model } \\
\text { Drop-out }\end{array}$}} & \multicolumn{6}{|c|}{ Working model } \\
\hline & & & \multicolumn{2}{|c|}{ GEE } & \multirow{2}{*}{$\frac{\text { WEE }}{\text { Exch }}$} & \multicolumn{2}{|c|}{ CWEE } & \multirow[t]{2}{*}{ ML } \\
\hline & Type & $\overline{\text { Amount }}$ & Indep & Exch & & Indep & Exch & \\
\hline 0.0 & $\begin{array}{l}\text { MCAR } \\
\text { MAR-weak } \\
\text { MAR-strong } \\
\text { MAR-2-dep } \\
\text { MNAR }\end{array}$ & $10 \%$ & $\begin{array}{r}0 \\
0 \\
2 \\
-2 \\
-47\end{array}$ & $\begin{array}{r}0 \\
0 \\
2 \\
-2 \\
-47\end{array}$ & $\begin{array}{r}0 \\
0 \\
2 \\
-2 \\
-47\end{array}$ & $\begin{array}{r}1 \\
1 \\
6 \\
-33 \\
-42\end{array}$ & $\begin{array}{r}1 \\
-2 \\
-4 \\
-52 \\
-43\end{array}$ & $\begin{array}{r}-0 \\
0 \\
2 \\
-2 \\
-46\end{array}$ \\
\hline 0.2 & $\begin{array}{l}\text { MCAR } \\
\text { MAR-weak } \\
\text { MAR-strong } \\
\text { MAR-2-dep } \\
\text { MNAR }\end{array}$ & & $\begin{array}{r}-7 \\
-10 \\
-27 \\
-35 \\
-69\end{array}$ & $\begin{array}{r}-7 \\
1 \\
2 \\
-1 \\
-59\end{array}$ & $\begin{array}{r}-7 \\
2 \\
2 \\
-5 \\
-63\end{array}$ & $\begin{array}{r}-4 \\
8 \\
4 \\
-44 \\
-97\end{array}$ & $\begin{array}{r}-4 \\
7 \\
1 \\
-35 \\
-87\end{array}$ & $\begin{array}{r}-7 \\
2 \\
3 \\
1 \\
-58\end{array}$ \\
\hline 0.6 & $\begin{array}{l}\text { MCAR } \\
\text { MAR-weak } \\
\text { MAR-strong } \\
\text { MAR-2-dep } \\
\text { MNAR }\end{array}$ & & $\begin{array}{r}-1 \\
-33 \\
-87 \\
-109 \\
-110\end{array}$ & $\begin{array}{r}-0 \\
1 \\
-2 \\
-3 \\
-46\end{array}$ & $\begin{array}{r}-1 \\
2 \\
1 \\
-9 \\
-55\end{array}$ & $\begin{array}{r}-3 \\
2 \\
0 \\
-39 \\
-101\end{array}$ & $\begin{array}{r}-3 \\
2 \\
1 \\
-10 \\
-76\end{array}$ & $\begin{array}{r}-0 \\
2 \\
1 \\
3 \\
-43\end{array}$ \\
\hline 0.0 & $\begin{array}{l}\text { MCAR } \\
\text { MAR-weak } \\
\text { MAR-strong } \\
\text { MAR-2-dep } \\
\text { MNAR }\end{array}$ & $20 \%$ & $\begin{array}{r}-4 \\
-2 \\
-0 \\
-5 \\
-95\end{array}$ & $\begin{array}{r}-5 \\
-2 \\
-0 \\
-5 \\
-95\end{array}$ & $\begin{array}{r}-5 \\
-2 \\
-0 \\
-4 \\
-95\end{array}$ & $\begin{array}{r}-4 \\
-5 \\
2 \\
-23 \\
-92\end{array}$ & $\begin{array}{r}-4 \\
-6 \\
-1 \\
-33 \\
-92\end{array}$ & $\begin{array}{r}-5 \\
-3 \\
0 \\
-3 \\
-93\end{array}$ \\
\hline 0.2 & $\begin{array}{l}\text { MCAR } \\
\text { MAR-weak } \\
\text { MAR-strong } \\
\text { MAR-2-dep } \\
\text { MNAR }\end{array}$ & & $\begin{array}{r}-8 \\
-22 \\
-56 \\
-68 \\
-139\end{array}$ & $\begin{array}{r}-7 \\
0 \\
-2 \\
-6 \\
-121\end{array}$ & $\begin{array}{r}-7 \\
1 \\
1 \\
-13 \\
-128\end{array}$ & $\begin{array}{r}-9 \\
1 \\
-3 \\
-38 \\
-153\end{array}$ & $\begin{array}{r}-7 \\
2 \\
-1 \\
-22 \\
-140\end{array}$ & $\begin{array}{r}-7 \\
1 \\
2 \\
-0 \\
-119\end{array}$ \\
\hline 0.6 & $\begin{array}{l}\text { MCAR } \\
\text { MAR-weak } \\
\text { MAR-strong } \\
\text { MAR-2-dep } \\
\text { MNAR }\end{array}$ & & $\begin{array}{r}-0 \\
-70 \\
-172 \\
-212 \\
-220\end{array}$ & $\begin{array}{r}-1 \\
-2 \\
-13 \\
-19 \\
-99\end{array}$ & $\begin{array}{r}-1 \\
-0 \\
-1 \\
-25 \\
-114\end{array}$ & $\begin{array}{r}-2 \\
-1 \\
-2 \\
-46 \\
-148\end{array}$ & $\begin{array}{r}-2 \\
-0 \\
-0 \\
-6 \\
-115\end{array}$ & $\begin{array}{r}-0 \\
1 \\
-2 \\
-2 \\
-89\end{array}$ \\
\hline 0.0 & $\begin{array}{l}\text { MCAR } \\
\text { MAR-weak } \\
\text { MAR-strong } \\
\text { MAR-2-dep } \\
\text { MNAR }\end{array}$ & $40 \%$ & $\begin{array}{r}-15 \\
-1 \\
-11 \\
-3 \\
-200\end{array}$ & $\begin{array}{r}-15 \\
-2 \\
-10 \\
-1 \\
-200\end{array}$ & $\begin{array}{r}-15 \\
-2 \\
-13 \\
-1 \\
-200\end{array}$ & $\begin{array}{r}-15 \\
-2 \\
-10 \\
11 \\
-200\end{array}$ & $\begin{array}{r}-15 \\
-3 \\
-14 \\
3 \\
-201\end{array}$ & $\begin{array}{r}-11 \\
4 \\
-1 \\
13 \\
-186\end{array}$ \\
\hline 0.2 & $\begin{array}{l}\text { MCAR } \\
\text { MAR-weak } \\
\text { MAR-strong } \\
\text { MAR-2-dep } \\
\text { MNAR }\end{array}$ & & $\begin{array}{r}-4 \\
-53 \\
-114 \\
-129 \\
-280\end{array}$ & $\begin{array}{r}-5 \\
-10 \\
-17 \\
-20 \\
-247\end{array}$ & $\begin{array}{r}-5 \\
-8 \\
-6 \\
-30 \\
-260\end{array}$ & $\begin{array}{r}-5 \\
-9 \\
-6 \\
-21 \\
-262\end{array}$ & $\begin{array}{r}-4 \\
-9 \\
-6 \\
2 \\
-247\end{array}$ & $\begin{array}{r}-4 \\
-9 \\
-6 \\
-10 \\
-235\end{array}$ \\
\hline 0.6 & $\begin{array}{l}\text { MCAR } \\
\text { MAR-weak } \\
\text { MAR-strong } \\
\text { MAR-2-dep } \\
\text { MNAR }\end{array}$ & & $\begin{array}{r}-9 \\
-152 \\
-331 \\
-399 \\
-439\end{array}$ & $\begin{array}{l}-10 \\
-15 \\
-48 \\
-66 \\
-218\end{array}$ & $\begin{array}{r}-9 \\
-14 \\
-11 \\
-77 \\
-242\end{array}$ & $\begin{array}{r}-9 \\
-15 \\
-10 \\
-76 \\
-243\end{array}$ & $\begin{array}{r}-6 \\
-4 \\
1 \\
1 \\
-190\end{array}$ & $\begin{array}{r}-6 \\
-8 \\
-10 \\
-17 \\
-186\end{array}$ \\
\hline
\end{tabular}

WEE-indep relative bias is the same as the reported WEE-exch relative bias rounded to nearest whole per cent. 
and the weighted GEE methods under MAR-weak and MAR-strong, the following general observations can be made: (i) for $K=50$, the bias is low for minimal or mild drop-out, but not for moderate drop-out; (ii) for $K=100$, the bias is low for mild and moderate drop-out, but not for severe drop-out; (iii) for $K=200$, the bias is low for mild, moderate and severe drop-out. Henceforth, and in agreement with simulation results to follow, we refer to mild, moderate and severe drop-out as the limiting missingness situations for $K=50, K=100$ and $K=200$, respectively, where these drop-out rates are sufficiently low such that they correspond to acceptable performance of $\hat{\beta}_{T}$ in this study. The one exception to these remarks is that the bias for CWEE is large for minimal drop-out in Table I. Indeed, the bias more than doubles those figures under limited simulations for 2 per cent drop-out (not shown), underscoring the poor properties of the CWEE method in situations where one would want a method to perform best.

All three tables show that use of GEE may result in biased estimates when drop-out is MAR. In particular, GEE with independence working correlation resulted in heavily biased estimates for non-zero correlation. This bias increased in absolute terms as the true correlation increased or as the strength of the MAR effect grew. Interestingly, GEE with exchangeable working correlation gave estimates with small bias under MAR-weak when the correlation was small $(\rho \leqslant 0.2)$. However, under limiting situations with MAR-strong and $\rho=0.6$ (for example, $K=100$ with 20 per cent drop-out; $K=200$ with 40 per cent drop-out) GEE with the correct exchangeable working correlation gave large bias. As noted earlier, WEE with independence or exchangeable correlation gave small bias in these cases under correctly specified MAR (weak or strong) mechanisms. However, under a misspecified missingness model (MAR-2-dep), the results show it is possible to have greater bias with weighted GEE than with GEE.

Tables IV to VI report on size. Table IV shows that the CWEE method can be very anticonservative when drop-out is minimal. When drop-out did not exceed that of the limiting situations for a given $K$, WEE performed well. Conversely, in some of those same situations, the test size of GEE was inflated, even when the exchangeable correlation was correctly specified. In particular, for $K=100$ with 20 per cent drop-out, $\rho=0.6$, and MAR-strong, the test size of GEE-exch was estimated to be 0.089 versus 0.048 for the WEE methods. For $K=200$ with 40 per cent drop-out, $\rho=0.6$, and MAR-strong, the test size of GEE-exch was estimated to be 0.108 , more than double the nominal 0.05 level, versus 0.051 for the WEE method. The test size for GEE-indep can be very inflated under MAR. Thus the results for test size parallel those for bias in that they are in general agreement with statements made above about the limiting situations of acceptable performance.

Tables VII and VIII report for these limiting situations, coverage of nominal 95 per cent confidence intervals for $\beta_{T}$ and performance of the standard errors of $\hat{\beta}_{T}$, respectively. We consider only MCAR and MAR corresponding to correctly specified drop-out models for the weighted GEE methods. For the weighted GEE methods, these results indicate coverage near the nominal 95 per cent level. Table VII shows that under MAR-strong and $\rho=0.6$, GEE may result in undercoverage. Table VIII shows that for the three methods that use an exchangeable working correlation matrix, the standard errors tend to slightly underestimate the true values. For $K=200$, the underestimation was less when drop-out was less (not shown). Results for the independence working correlation are similar to those shown in Table VIII. Generally, these results along with the confidence interval coverage close to the nominal 95 per cent level indicates that the variance estimators (along with asymptotic normality) are reasonable for the limiting situations. 
Table IV. Size of $\beta_{6}$ (probability $\left.\times 1000\right), K=50, T=6$.

\begin{tabular}{|c|c|c|c|c|c|c|c|}
\hline \multirow[t]{3}{*}{$\bar{\rho}$} & \multirow{2}{*}{\multicolumn{2}{|c|}{$\begin{array}{c}\text { True model } \\
\text { Drop-out }\end{array}$}} & \multicolumn{5}{|c|}{ Working model } \\
\hline & & & \multicolumn{2}{|c|}{ GEE } & \multirow{2}{*}{$\frac{\text { WEE }}{\text { Exch }}$} & \multicolumn{2}{|c|}{ CWEE } \\
\hline & Type & Amount & Indep & Exch & & Indep & Exch \\
\hline \multirow[t]{5}{*}{0.0} & MCAR & $5 \%$ & 40 & 40 & 43 & 88 & 93 \\
\hline & MAR-weak & & 39 & 39 & 40 & 101 & 99 \\
\hline & MAR-strong & & 46 & 46 & 48 & 118 & 114 \\
\hline & MAR-2-dep & & 39 & 39 & 40 & 141 & 130 \\
\hline & MNAR & & 39 & 39 & 41 & 98 & 105 \\
\hline \multirow[t]{5}{*}{0.2} & MCAR & & 55 & 50 & 58 & 111 & 120 \\
\hline & MAR-weak & & 50 & 55 & 54 & 100 & 92 \\
\hline & MAR-strong & & 48 & 50 & 49 & 112 & 113 \\
\hline & MAR-2-dep & & 52 & 55 & 52 & 101 & 106 \\
\hline & MNAR & & 38 & 35 & 39 & 83 & 101 \\
\hline \multirow[t]{5}{*}{0.6} & MCAR & & 41 & 41 & 47 & 80 & 87 \\
\hline & MAR-weak & & 48 & 49 & 50 & 63 & 87 \\
\hline & MAR-strong & & 56 & 54 & 46 & 80 & 71 \\
\hline & MAR-2-dep & & 95 & 64 & 52 & 74 & 74 \\
\hline & MNAR & & 63 & 52 & 57 & 94 & 92 \\
\hline \multirow[t]{5}{*}{0.0} & MCAR & $10 \%$ & 44 & 45 & 46 & 53 & 54 \\
\hline & MAR-weak & & 42 & 40 & 41 & 60 & 53 \\
\hline & MAR-strong & & 51 & 51 & 50 & 67 & 66 \\
\hline & MAR-2-dep & & 43 & 43 & 44 & 63 & 62 \\
\hline & MNAR & & 31 & 31 & 33 & 46 & 44 \\
\hline \multirow[t]{5}{*}{0.2} & MCAR & & 44 & 51 & 50 & 54 & 48 \\
\hline & MAR-weak & & 47 & 50 & 49 & 69 & 59 \\
\hline & MAR-strong & & 51 & 51 & 56 & 67 & 67 \\
\hline & MAR-2-dep & & 45 & 60 & 53 & 73 & 75 \\
\hline & MNAR & & 54 & 51 & 48 & 57 & 59 \\
\hline \multirow[t]{5}{*}{0.6} & MCAR & & 39 & 41 & 45 & 55 & 55 \\
\hline & MAR-weak & & 50 & 55 & 53 & 47 & 57 \\
\hline & MAR-strong & & 72 & 55 & 39 & 67 & 59 \\
\hline & MAR-2-dep & & 153 & 73 & 42 & 61 & 67 \\
\hline & MNAR & & 102 & 72 & 61 & 81 & 77 \\
\hline \multirow[t]{5}{*}{0.0} & MCAR & $20 \%$ & 40 & 43 & 41 & 37 & 37 \\
\hline & MAR-weak & & 34 & 37 & 42 & 41 & 41 \\
\hline & MAR-strong & & 42 & 41 & 52 & 44 & 43 \\
\hline & MAR-2-dep & & 34 & 36 & 48 & 54 & 53 \\
\hline & MNAR & & 18 & 17 & 21 & 22 & 15 \\
\hline \multirow[t]{5}{*}{0.2} & MCAR & & 45 & 48 & 53 & 45 & 48 \\
\hline & MAR-weak & & 34 & 49 & 40 & 43 & 46 \\
\hline & MAR-strong & & 42 & 58 & 48 & 47 & 47 \\
\hline & MAR-2-dep & & 50 & 70 & 54 & 68 & 76 \\
\hline & MNAR & & 44 & 48 & 45 & 49 & 57 \\
\hline \multirow[t]{5}{*}{0.6} & MCAR & & 29 & 50 & 39 & 41 & 56 \\
\hline & MAR-weak & & 30 & 58 & 42 & 39 & 51 \\
\hline & MAR-strong & & 78 & 85 & 59 & 66 & 77 \\
\hline & MAR-2-dep & & 146 & 115 & 47 & 57 & 84 \\
\hline & MNAR & & 92 & 121 & 31 & 48 & 68 \\
\hline
\end{tabular}

WEE-indep test size is the same as the reported WEE-exch test size. 
Table V. Size of $\beta_{6}($ probability $\times 1000), K=100, T=6$.

\begin{tabular}{|c|c|c|c|c|c|c|c|}
\hline \multirow[t]{3}{*}{$\rho$} & \multirow{2}{*}{\multicolumn{2}{|c|}{$\begin{array}{c}\text { True model } \\
\text { Drop-out }\end{array}$}} & \multicolumn{5}{|c|}{ Working model } \\
\hline & & & \multicolumn{2}{|c|}{ GEE } & \multirow{2}{*}{$\frac{\text { WEE }}{\text { Exch }}$} & \multicolumn{2}{|c|}{ CWEE } \\
\hline & Type & Amount & Indep & Exch & & Indep & Exch \\
\hline \multirow[t]{5}{*}{0.0} & MCAR & $10 \%$ & 44 & 42 & 45 & 50 & 51 \\
\hline & MAR-weak & & 45 & 43 & 45 & 43 & 39 \\
\hline & MAR-strong & & 52 & 52 & 54 & 68 & 69 \\
\hline & MAR-2-dep & & 45 & 47 & 51 & 62 & 69 \\
\hline & MNAR & & 44 & 45 & 45 & 47 & 42 \\
\hline \multirow[t]{5}{*}{0.2} & MCAR & & 50 & 54 & 54 & 50 & 44 \\
\hline & MAR-weak & & 52 & 59 & 64 & 61 & 60 \\
\hline & MAR-strong & & 56 & 52 & 51 & 50 & 55 \\
\hline & MAR-2-dep & & 56 & 47 & 43 & 67 & 63 \\
\hline & MNAR & & 80 & 77 & 74 & 86 & 86 \\
\hline \multirow[t]{5}{*}{0.6} & MCAR & & 61 & 54 & 58 & 48 & 53 \\
\hline & MAR-weak & & 69 & 50 & 45 & 53 & 46 \\
\hline & MAR-strong & & 181 & 61 & 49 & 68 & 68 \\
\hline & MAR-2-dep & & 266 & 74 & 50 & 61 & 57 \\
\hline & MNAR & & 196 & 76 & 85 & 108 & 98 \\
\hline \multirow[t]{5}{*}{0.0} & MCAR & $20 \%$ & 37 & 40 & 42 & 41 & 41 \\
\hline & MAR-weak & & 47 & 44 & 46 & 42 & 39 \\
\hline & MAR-strong & & 54 & 52 & 52 & 57 & 58 \\
\hline & MAR-2-dep & & 36 & 41 & 46 & 53 & 56 \\
\hline & MNAR & & 40 & 42 & 41 & 42 & 40 \\
\hline \multirow[t]{5}{*}{0.2} & MCAR & & 40 & 39 & 44 & 50 & 42 \\
\hline & MAR-weak & & 43 & 47 & 47 & 55 & 51 \\
\hline & MAR-strong & & 66 & 47 & 49 & 45 & 54 \\
\hline & MAR-2-dep & & 82 & 63 & 54 & 51 & 66 \\
\hline & MNAR & & 105 & 93 & 97 & 104 & 102 \\
\hline \multirow[t]{5}{*}{0.6} & MCAR & & 42 & 48 & 44 & 45 & 44 \\
\hline & MAR-weak & & 85 & 57 & 49 & 59 & 46 \\
\hline & MAR-strong & & 284 & 89 & 48 & 60 & 66 \\
\hline & MAR-2-dep & & 417 & 106 & 49 & 53 & 72 \\
\hline & MNAR & & 356 & 172 & 107 & 129 & 108 \\
\hline \multirow[t]{5}{*}{0.0} & MCAR & $40 \%$ & 18 & 22 & 23 & 24 & 29 \\
\hline & MAR-weak & & 14 & 20 & 18 & 20 & 26 \\
\hline & MAR-strong & & 23 & 27 & 46 & 50 & 47 \\
\hline & MAR-2-dep & & 18 & 22 & 33 & 39 & 41 \\
\hline & MNAR & & 8 & 13 & 8 & 11 & 12 \\
\hline \multirow[t]{5}{*}{0.2} & MCAR & & 12 & 48 & 20 & 23 & 51 \\
\hline & MAR-weak & & 15 & 65 & 34 & 40 & 73 \\
\hline & MAR-strong & & 6 & 70 & 63 & 68 & 82 \\
\hline & MAR-2-dep & & 13 & 74 & 55 & 55 & 79 \\
\hline & MNAR & & 17 & 90 & 25 & 19 & 67 \\
\hline \multirow[t]{5}{*}{0.6} & MCAR & & 15 & 92 & 24 & 23 & 78 \\
\hline & MAR-weak & & 2 & 133 & 41 & 41 & 112 \\
\hline & MAR-strong & & 22 & 191 & 77 & 83 & 151 \\
\hline & MAR-2-dep & & 96 & 254 & 86 & 77 & 194 \\
\hline & MNAR & & 45 & 360 & 17 & 15 & 194 \\
\hline
\end{tabular}

WEE-indep test size is the same as the reported WEE-exch test size except table entry is 21 for (drop-out $=40$ per cent, $\rho=0.2$, MCAR). 
Table VI. Size of $\beta_{4}$ (probability $\left.\times 1000\right), K=200, T=4$.

\begin{tabular}{|c|c|c|c|c|c|c|c|c|}
\hline \multirow[t]{3}{*}{$\bar{\rho}$} & \multirow{2}{*}{\multicolumn{2}{|c|}{$\begin{array}{c}\text { True model } \\
\text { Drop-out }\end{array}$}} & \multicolumn{6}{|c|}{ Working model } \\
\hline & & & \multicolumn{2}{|c|}{ GEE } & \multirow{2}{*}{$\frac{\text { WEE }}{\text { Exch }}$} & \multicolumn{2}{|c|}{ CWEE } & \multirow[t]{2}{*}{ ML } \\
\hline & Type & Amount & Indep & Exch & & Indep & Exch & \\
\hline \multirow[t]{5}{*}{0.0} & MCAR & $10 \%$ & 49 & 50 & 49 & 47 & 54 & 49 \\
\hline & MAR-weak & & 35 & 35 & 34 & 40 & 43 & 38 \\
\hline & MAR-strong & & 44 & 44 & 47 & 61 & 62 & 47 \\
\hline & MAR-2-dep & & 46 & 47 & 48 & 58 & 71 & 48 \\
\hline & MNAR & & 68 & 69 & 69 & 61 & 57 & 68 \\
\hline \multirow[t]{5}{*}{0.2} & MCAR & & 51 & 51 & 51 & 59 & 59 & 52 \\
\hline & MAR-weak & & 77 & 73 & 75 & 78 & 76 & 73 \\
\hline & MAR-strong & & 49 & 44 & 47 & 68 & 67 & 48 \\
\hline & MAR-2-dep & & 45 & 39 & 39 & 64 & 70 & 38 \\
\hline & MNAR & & 94 & 82 & 88 & 119 & 121 & 83 \\
\hline \multirow[t]{5}{*}{0.6} & MCAR & & 50 & 59 & 62 & 54 & 60 & 58 \\
\hline & MAR-weak & & 71 & 45 & 49 & 52 & 51 & 43 \\
\hline & MAR-strong & & 160 & 38 & 36 & 58 & 52 & 40 \\
\hline & MAR-2-dep & & 238 & 60 & 53 & 63 & 58 & 50 \\
\hline & MNAR & & 261 & 100 & 106 & 140 & 119 & 74 \\
\hline \multirow[t]{5}{*}{0.0} & MCAR & $20 \%$ & 53 & 51 & 56 & 52 & 51 & 50 \\
\hline & MAR-weak & & 41 & 41 & 43 & 38 & 39 & 42 \\
\hline & MAR-strong & & 54 & 52 & 50 & 53 & 51 & 48 \\
\hline & MAR-2-dep & & 56 & 51 & 53 & 54 & 63 & 53 \\
\hline & MNAR & & 98 & 100 & 101 & 96 & 96 & 98 \\
\hline \multirow[t]{5}{*}{0.2} & MCAR & & 42 & 39 & 40 & 44 & 43 & 50 \\
\hline & MAR-weak & & 75 & 74 & 74 & 70 & 75 & 68 \\
\hline & MAR-strong & & 59 & 46 & 44 & 41 & 40 & 46 \\
\hline & MAR-2-dep & & 81 & 43 & 43 & 53 & 51 & 43 \\
\hline & MNAR & & 197 & 159 & 166 & 191 & 181 & 149 \\
\hline \multirow[t]{5}{*}{0.6} & MCAR & & 48 & 61 & 57 & 57 & 52 & 60 \\
\hline & MAR-weak & & 101 & 50 & 42 & 47 & 45 & 43 \\
\hline & MAR-strong & & 362 & 48 & 39 & 33 & 36 & 37 \\
\hline & MAR-2-dep & & 508 & 72 & 51 & 63 & 47 & 45 \\
\hline & MNAR & & 538 & 218 & 203 & 230 & 220 & 138 \\
\hline \multirow[t]{5}{*}{0.0} & MCAR & $40 \%$ & 55 & 56 & 56 & 52 & 54 & 64 \\
\hline & MAR-weak & & 42 & 39 & 43 & 47 & 44 & 39 \\
\hline & MAR-strong & & 45 & 44 & 45 & 41 & 41 & 37 \\
\hline & MAR-2-dep & & 45 & 50 & 52 & 61 & 58 & 44 \\
\hline & MNAR & & 161 & 163 & 167 & 169 & 169 & 155 \\
\hline \multirow[t]{5}{*}{0.2} & MCAR & & 40 & 44 & 44 & 41 & 44 & 47 \\
\hline & MAR-weak & & 54 & 59 & 55 & 55 & 60 & 58 \\
\hline & MAR-strong & & 85 & 57 & 47 & 50 & 42 & 35 \\
\hline & MAR-2-dep & & 95 & 50 & 55 & 50 & 51 & 46 \\
\hline & MNAR & & 313 & 291 & 284 & 280 & 267 & 216 \\
\hline \multirow[t]{5}{*}{0.6} & MCAR & & 38 & 51 & 42 & 44 & 57 & 41 \\
\hline & MAR-weak & & 117 & 65 & 44 & 43 & 43 & 44 \\
\hline & MAR-strong & & 512 & 108 & 51 & 45 & 55 & 33 \\
\hline & MAR-2-dep & & 670 & 158 & 63 & 56 & 82 & 37 \\
\hline & MNAR & & 721 & 437 & 249 & 232 & 241 & 145 \\
\hline
\end{tabular}

WEE-indep test size is the same as the reported WEE-exch test size for all rows. 
Table VII. Coverage of nominal 95 per cent confidence intervals for $\beta_{T}$.

\begin{tabular}{|c|c|c|c|c|c|c|c|c|c|}
\hline \multirow[t]{3}{*}{$K$} & \multirow[t]{3}{*}{$T$} & \multirow[t]{3}{*}{$\rho$} & \multirow{2}{*}{\multicolumn{2}{|c|}{$\begin{array}{c}\text { True model } \\
\text { Drop-out }\end{array}$}} & \multicolumn{5}{|c|}{ Working model } \\
\hline & & & & & \multicolumn{2}{|c|}{ GEE } & \multirow{2}{*}{$\frac{\text { WEE }}{\text { Exch }}$} & \multicolumn{2}{|c|}{ CWEE } \\
\hline & & & Type & Amount & Indep & Exch & & Indep & Exch \\
\hline \multirow[t]{9}{*}{50} & 6 & 0.0 & MCAR & $10 \%$ & 94.8 & 94.6 & 94.7 & 94.4 & 93.9 \\
\hline & & & MAR-weak & & 96.3 & 96.1 & 95.9 & 94.4 & 94.6 \\
\hline & & & MAR-strong & & 96.0 & 96.2 & 95.4 & 93.3 & 93.4 \\
\hline & & 0.2 & MCAR & & 96.0 & 95.7 & 95.2 & 95.7 & 95.6 \\
\hline & & & MAR-weak & & 94.9 & 94.2 & 94.2 & 93.1 & 93.5 \\
\hline & & & MAR-strong & & 95.1 & 94.9 & 94.6 & 93.9 & 93.4 \\
\hline & & 0.6 & MCAR & & 96.0 & 95.5 & 95.6 & 93.8 & 94.2 \\
\hline & & & MAR-weak & & 93.7 & 95.1 & 95.2 & 95.0 & 95.3 \\
\hline & & & MAR-strong & & 91.8 & 94.7 & 96.1 & 93.9 & 94.5 \\
\hline \multirow[t]{9}{*}{100} & 6 & 0.0 & MCAR & $20 \%$ & 94.9 & 95.2 & 94.6 & 95.3 & 95.8 \\
\hline & & & MAR-weak & & 95.2 & 95.2 & 95.1 & 95.5 & 95.4 \\
\hline & & & MAR-strong & & 94.6 & 94.6 & 94.4 & 94.4 & 94.7 \\
\hline & & 0.2 & MCAR & & 94.6 & 94.7 & 94.5 & 94.8 & 94.5 \\
\hline & & & MAR-weak & & 94.8 & 94.9 & 94.5 & 95.4 & 95.1 \\
\hline & & & MAR-strong & & 93.2 & 94.3 & 94.3 & 95.0 & 94.5 \\
\hline & & 0.6 & MCAR & & 95.4 & 94.6 & 95.0 & 95.8 & 95.0 \\
\hline & & & MAR-weak & & 92.0 & 94.5 & 94.0 & 93.3 & 94.5 \\
\hline & & & MAR-strong & & 71.3 & 92.5 & 95.7 & 94.9 & 94.0 \\
\hline \multirow[t]{9}{*}{200} & 4 & 0.0 & MCAR & $40 \%$ & 94.3 & 94.1 & 93.8 & 94.1 & 94.1 \\
\hline & & & MAR-weak & & 95.4 & 95.6 & 95.4 & 95.4 & 95.3 \\
\hline & & & MAR-strong & & 96.2 & 96.2 & 95.8 & 94.9 & 94.8 \\
\hline & & 0.2 & MCAR & & 95.0 & 95.0 & 94.9 & 95.5 & 95.4 \\
\hline & & & MAR-weak & & 94.0 & 94.1 & 93.9 & 94.1 & 93.8 \\
\hline & & & MAR-strong & & 91.2 & 93.9 & 94.5 & 95.4 & 95.3 \\
\hline & & 0.6 & MCAR & & 96.7 & 95.4 & 95.5 & 95.5 & 95.7 \\
\hline & & & MAR-weak & & 88.6 & 94.0 & 96.1 & 96.4 & 96.2 \\
\hline & & & MAR-strong & & 48.7 & 88.6 & 95.1 & 95.1 & 95.1 \\
\hline
\end{tabular}

WEE-indep coverage is the same as the reported WEE-exch coverage rounded to nearest tenth except for three cases: (i) (drop-out $=20$ per cent, $\rho=0.2$, MAR-strong) $=94.4$; (ii) (drop-out $=40$ per cent, $\rho=0$, MAR-weak $)=97.4$; (iii) $($ drop-out $=40$ per cent, $\rho=0.6$, MAR-weak $)=96.0$.

Table IX reports per cent relative efficiency with respect to maximum likelihood of GEE and the two weighted GEE methods for $K=200, T=4$. The efficiency of WEE, like that of GEE with correctly specified exchangeable working correlation, was generally high. Efficiency for these methods decreased with increasing drop-out and correlation as illustrated with 40 per cent drop-out and $\rho=0.6$ when efficiency of WEE and GEE-exch was 70 per cent and 26 per cent, respectively. The low efficiency for GEE-exch in this case is related to its large bias as shown in Table III. We note that when $T=4$ under 40 per cent drop-out, only 22 per 
Table VIII. Average standard errors (SE) and Monte Carlo standard deviation (SD) of $\hat{\beta}_{T}\left(\times 10^{3}\right)$.

\begin{tabular}{|c|c|c|c|c|c|c|c|c|c|c|}
\hline \multirow[t]{3}{*}{$\bar{K}$} & \multirow[t]{3}{*}{$T$} & \multirow[t]{3}{*}{$\rho$} & \multirow{2}{*}{\multicolumn{2}{|c|}{$\begin{array}{c}\text { True model } \\
\text { Drop-out }\end{array}$}} & \multicolumn{6}{|c|}{ Working model } \\
\hline & & & & & \multicolumn{2}{|c|}{ GEE } & \multicolumn{2}{|c|}{ WEE } & \multicolumn{2}{|c|}{ CWEE } \\
\hline & & & Type & Amount & $\mathrm{SE}$ & SD & SE & SD & SE & SD \\
\hline \multirow[t]{9}{*}{50} & 6 & 0.0 & MCAR & $10 \%$ & 494 & 520 & 489 & 520 & 586 & 647 \\
\hline & & & MAR-weak & & 492 & 507 & 487 & 505 & 594 & 648 \\
\hline & & & MAR-strong & & 489 & 490 & 486 & 491 & 616 & 668 \\
\hline & & 0.2 & MCAR & & 450 & 469 & 449 & 472 & 515 & 555 \\
\hline & & & MAR-weak & & 443 & 474 & 446 & 478 & 518 & 571 \\
\hline & & & MAR-strong & & 440 & 466 & 449 & 482 & 531 & 594 \\
\hline & & 0.6 & MCAR & & 317 & 326 & 328 & 340 & 364 & 401 \\
\hline & & & MAR-weak & & 318 & 333 & 333 & 350 & 366 & 380 \\
\hline & & & MAR-strong & & 315 & 329 & 344 & 351 & 373 & 395 \\
\hline \multirow[t]{9}{*}{100} & 6 & 0.0 & MCAR & $20 \%$ & 427 & 439 & 424 & 440 & 442 & 457 \\
\hline & & & MAR-weak & & 421 & 439 & 419 & 440 & 440 & 460 \\
\hline & & & MAR-strong & & 413 & 433 & 416 & 442 & 452 & 485 \\
\hline & & 0.2 & MCAR & & 392 & 400 & 397 & 407 & 405 & 413 \\
\hline & & & MAR-weak & & 381 & 403 & 393 & 417 & 401 & 421 \\
\hline & & & MAR-strong & & 372 & 397 & 402 & 437 & 418 & 444 \\
\hline & & 0.6 & MCAR & & 283 & 296 & 310 & 326 & 293 & 309 \\
\hline & & & MAR-weak & & 275 & 286 & 313 & 335 & 292 & 297 \\
\hline & & & MAR-strong & & 265 & 292 & 339 & 352 & 303 & 321 \\
\hline \multirow[t]{9}{*}{200} & 4 & 0.0 & MCAR & $40 \%$ & 357 & 373 & 355 & 374 & 360 & 378 \\
\hline & & & MAR-weak & & 345 & 344 & 345 & 347 & 352 & 353 \\
\hline & & & MAR-strong & & 334 & 338 & 346 & 358 & 358 & 369 \\
\hline & & 0.2 & MCAR & & 333 & 341 & 336 & 346 & 335 & 345 \\
\hline & & & MAR-weak & & 322 & 342 & 333 & 355 & 332 & 351 \\
\hline & & & MAR-strong & & 305 & 316 & 340 & 339 & 339 & 336 \\
\hline & & 0.6 & MCAR & & 248 & 254 & 273 & 281 & 249 & 256 \\
\hline & & & MAR-weak & & 235 & 248 & 275 & 283 & 243 & 247 \\
\hline & & & MAR-strong & & 224 & 249 & 299 & 307 & 250 & 260 \\
\hline
\end{tabular}

Working model uses exchangeable correlation matrix.

cent of subjects have complete data. Lastly, the efficiency of CWEE was consistently poor, with the worst relative performance for the least amount of drop-out.

\section{DISCUSSION}

The simulation study presented in this paper illustrated that robustness to choice of working correlation in GEE does not generally hold in cases where the data are not missing completely 
Table IX. Efficiency of $\hat{\beta}_{4}, K=200, T=4$.

\begin{tabular}{|c|c|c|c|c|c|c|c|}
\hline \multirow[t]{3}{*}{$\rho$} & \multirow{2}{*}{\multicolumn{2}{|c|}{$\begin{array}{c}\text { True model } \\
\text { Drop-out }\end{array}$}} & \multicolumn{5}{|c|}{ Working model } \\
\hline & & & \multicolumn{2}{|c|}{ GEE } & \multirow{2}{*}{$\frac{\text { WEE }}{\text { Exch }}$} & \multicolumn{2}{|c|}{ CWEE } \\
\hline & Type & Amount & Indep & Exch & & Indep & Exch \\
\hline \multirow[t]{3}{*}{0.0} & MCAR & $10 \%$ & 100 & 100 & 100 & 67 & 65 \\
\hline & MAR-weak & & 101 & 101 & 101 & 68 & 64 \\
\hline & MAR-strong & & 101 & 101 & 101 & 58 & 54 \\
\hline \multirow[t]{3}{*}{0.2} & MCAR & & 99 & 99 & 99 & 65 & 70 \\
\hline & MAR-weak & & 82 & 101 & 99 & 56 & 62 \\
\hline & MAR-strong & & 38 & 103 & 101 & 52 & 57 \\
\hline \multirow[t]{3}{*}{0.6} & MCAR & & 88 & 100 & 96 & 50 & 65 \\
\hline & MAR-weak & & 18 & 101 & 99 & 54 & 69 \\
\hline & MAR-strong & & 3 & 96 & 95 & 45 & 59 \\
\hline \multirow[t]{3}{*}{0.0} & MCAR & $20 \%$ & 101 & 100 & 100 & 92 & 90 \\
\hline & MAR-weak & & 101 & 101 & 100 & 89 & 87 \\
\hline & MAR-strong & & 103 & 103 & 101 & 86 & 84 \\
\hline \multirow[t]{3}{*}{0.2} & MCAR & & 96 & 100 & 98 & 83 & 90 \\
\hline & MAR-weak & & 55 & 101 & 100 & 83 & 89 \\
\hline & MAR-strong & & 14 & 103 & 100 & 77 & 85 \\
\hline \multirow[t]{3}{*}{0.6} & MCAR & & 80 & 100 & 94 & 69 & 89 \\
\hline & MAR-weak & & 6 & 99 & 94 & 71 & 90 \\
\hline & MAR-strong & & 1 & 65 & 92 & 64 & 87 \\
\hline \multirow[t]{3}{*}{0.0} & MCAR & $40 \%$ & 95 & 94 & 94 & 92 & 91 \\
\hline & MAR-weak & & 104 & 104 & 102 & 99 & 98 \\
\hline & MAR-strong & & 98 & 98 & 84 & 84 & 79 \\
\hline \multirow[t]{3}{*}{0.2} & MCAR & & 97 & 101 & 98 & 95 & 100 \\
\hline & MAR-weak & & 32 & 99 & 95 & 92 & 96 \\
\hline & MAR-strong & & 8 & 87 & 94 & 89 & 95 \\
\hline \multirow[t]{3}{*}{0.6} & MCAR & & 60 & 86 & 73 & 67 & 92 \\
\hline & MAR-weak & & 3 & 79 & 67 & 61 & 106 \\
\hline & MAR-strong & & 1 & 26 & 70 & 69 & 111 \\
\hline
\end{tabular}

Efficiency $=100 \times \operatorname{mse}\left(\hat{\beta}_{T, \mathrm{ML}}\right) / \mathrm{mse}\left(\hat{\beta}_{T, \mathrm{EE}}\right)$, where EE is the estimating equations method and $\mathrm{ML}$ is maximum likelihood. WEE-indep efficiency is the same as the reported WEE-exch efficiency rounded to nearest whole per cent.

at random [2]. Additionally, we demonstrated that GEE may perform poorly when data are MAR even when the correlation structure is correctly specified. Lipsitz et al. [10] have proposed a modified GEE approach for handling missing response data that is based upon an alternative estimator for $\rho$. In a simulation study of longitudinal binary data with two time points, it yielded regression parameter estimates with less bias than the standard GEE when the data are MAR and the correlation structure has been correctly specified. 
Under MAR, the weighted GEE using observation specific weights [12] performed well, in terms of bias and efficiency, for estimating trends in longitudinal data. Its success, however, depended upon a correctly specified model for the missing data mechanism. Under a misspecified drop-out model, we demonstrated that it is possible to have worse performance with weighted GEE than with GEE. Lipsitz et al. [10] reported similar findings for a model with both an observation and a cluster-level covariate.

The results of the simulation study suggest that the weighted GEE procedure with clusterlevel weights [13] should not be used as a general method. It can be considerably less efficient than the observation-weighted GEE. This finding is consistent with an earlier report in a different setting [15]. To see why the cluster-level weights may be very inefficient, reconsider the case where the missingness probability is small $\left(\alpha_{0}=3.0\right)$. The probability of observing only the first response is low, and the few such clusters receive a large weight, even though these clusters contain the least information on the time trend parameter $\beta_{T}$. Indeed, the weighted GEE with cluster-level weights gave large bias when $K=50$ with minimal drop-out.

We found that variance estimators for all six methods tended to underestimate the true variance of the regression parameter estimates to similar degrees. Adjustments to the weighted GEE variance estimators like those proposed for GEE [21] may be needed in small samples. There may be some interest in using (4) with $S_{i}=0, i=1, \ldots, K$ since these may be easily obtained by adapting existing software. This approach is conservative. In results for $K=200$, $n=4$ (not shown), we found that such procedures resulted in the average of the standard errors being up to 15 per cent greater than the corresponding Monte Carlo estimate.

The simulation study did not reveal an efficiency gain by using the correct exchangeable correlation in WEE relative to an independence working correlation assumption. In other settings, the choice of the working correlation matrix in equation (2) may affect efficiency [14]. For 200 clusters with maximum cluster size of 4, we found that the weighted GEE with observation level weights had high efficiency except in the notable case of severe drop-out (40 per cent conditional drop-out or 22 per cent completers) and high intracluster correlation $(\rho=0.6)$. Relative to unweighted GEE and CWEE, it was overall the most efficient. We did not examine the semi-parametric efficient estimator [22].

\section{APPENDIX}

Suppose we wish to simulate $Y$, a $T$-vector of Bernoulli variates with mean vector $\pi$ and covariance matrix $V$. For $t=2, \ldots, T$, define $Z_{t}=\left(Y_{1}, \ldots, Y_{t-1}\right)^{\top}, \mu_{t}=E\left(Z_{t}\right), G_{t}=\operatorname{cov}\left(Z_{t}\right)$, and $s_{t}=\operatorname{cov}\left(Z_{t}, Y_{t}\right)$. Note that $G_{t}$ and $s_{t}$ are determined from $V$. For a given $(\pi, V)$, a $(t-1)$ vector $b_{t}$ is defined as $b_{t}=G_{t}^{-1} s_{t}(t=2, \ldots, T)$. The conditional linear family (introduced in an unpublished work by Bahjat Qaqish) is defined by

$$
\begin{aligned}
v_{t} & =v_{t}\left(z_{t} ; \pi, V\right):=P\left(Y_{t}=1 \mid Z_{t}=z_{t}\right)=\pi_{t}+b_{t}^{\top}\left(z_{t}-\mu_{t}\right) \\
& =\pi_{t}+\sum_{j=1}^{t-1} b_{t j}\left(y_{j}-\pi_{j}\right) \quad(t=2, \ldots, T)
\end{aligned}
$$

The simulation algorithm proceeds as follows. First, simulate $Y_{1}$ as Bernoulli with mean $\pi_{1}$, then for $t=2, \ldots, T$, simulate $Y_{t}$ as Bernoulli with conditional mean $v_{t}$ given by (A1). It then 
follows that $E(Y)=\pi$ and for $1<t \leqslant T, \operatorname{cov}\left(Z_{t}, Y_{t}\right)=\operatorname{cov}\left(Z_{t}, b_{t}^{\top} Z_{t}\right)=G_{t} b_{t}=s_{t}$. The vector $Y$ thus obtained has the required mean, $\pi$, and covariance, $V$. There are some restrictions on allowable $\pi$ and $V$ as discussed by Qaqish.

The full joint distribution of $Y$, whose explicit specification is not required, can be computed via (A1). For any valid $(\pi, V)$ that is reproducible by the conditional linear family, there is a corresponding unique value of the $2^{T} \times 1$ vector $\theta$ of joint probabilities. For $T=4$ and exchangeable correlation, let $\theta_{i j k l}=P\left(Y_{1}=i, Y_{2}=j, Y_{3}=k, Y_{4}=l\right)$ and $\theta^{\mathrm{T}}(\pi, \rho)=\left\{\theta_{0000}, \theta_{0001}, \ldots\right.$, $\left.\theta_{1111}\right\}$ be the $2^{4}$ vector of joint probabilities with the later indices changing fastest. Letting $\pi_{0}$ $=(0.332,0.348,0.362,0.378)$, the simulation results in Tables III, IX and the bottom thirds of Tables VII and VIII were based upon generating $T=4$ correlated Bernoulli variates from:

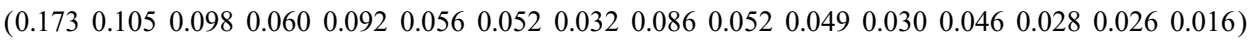

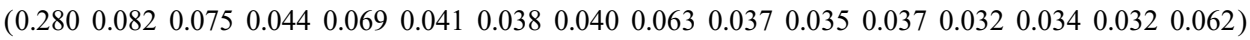

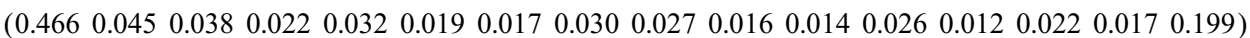

the values of $\theta^{\mathrm{T}}\left(\pi_{0}, 0\right), \theta^{\mathrm{T}}\left(\pi_{0}, 0.2\right)$, and $\theta^{\mathrm{T}}\left(\pi_{0}, 0.6\right)$, respectively.

\section{ACKNOWLEDGEMENTS}

We thank Bahjat F. Qaqish for help in regards to generating correlated binary data, and Michael E. Miller and two anonymous referees for comments leading to improvements in the paper. An earlier draft was written while J. Preisser was on the faculty of Wake Forest University School of Medicine, Winston-Salem, NC. The work was partially supported by grant IRG-198A from the American Cancer Society. K. Lohman acknowledges support from grant AG14131 from the National Institutes of Health.

\section{REFERENCES}

1. Diggle PJ, Liang K-Y, Zeger SL. Analysis of Longitudinal Data. Oxford University Press: Oxford, 1994.

2. Liang K-Y, Zeger SL. Longitudinal data analysis using generalized linear models. Biometrika 1986; 73:13-22.

3. Hendricks SA, Wassell JT, Collins JW, Sedlak SL. Power determinations for geographically clustered data using generalized estimating equations. Statistics in Medicine 1996; 15:1951-1960.

4. Carr GJ, Portier CJ. An evaluation of some methods for fitting dose-response models to quantal-response developmental toxicology data. Biometrics 1993; 49:779-791.

5. Bieler GS, Williams RL. Cluster sampling techniques in quantal response teratology and developmental toxicity studies. Biometrics 1995; 51:764-776.

6. Sharples K, Breslow N. Regression analysis of correlated binary data: some small sample results for the estimating equation approach. Journal of Statistical Computation and Simulation 1992; 42:1-20.

7. Emrich LJ, Piedmonte MR. On some small sample properties of generalized estimating equation estimates for multivariate dichotomous outcomes. Journal of Statistical Computation and Simulation 1992; 41:19-29.

8. Lipsitz SR, Fitzmaurice GM, Orav EJ, Laird NM. Performance of generalized estimating equations in practical situations. Biometrics 1994; 50:270-278.

9. Gunsolley JC, Getchell C, Chinchilli VM. Small sample characteristics of generalized estimating equations. Communications in Statistics-Simulations 1995; 24:869-878.

10. Lipsitz SR, Molenberghs G, Fitzmaurice GM, Ibrahim J. GEE with Gaussian estimation of the correlations when data are incomplete. Biometrics 2000; 56:528-536.

11. Preisser JS, Galecki AT, Lohman KK, Wagenknecht LE. Analysis of smoking trends with incomplete longitudinal binary responses. Journal of the American Statistical Association 2000; 95:1021-1031.

12. Robins JM, Rotnitzky A, Zhao LP. Analysis of semiparametric regression models for repeated outcomes in the presence of missing data. Journal of the American Statistical Association 1995; 90:106-121.

13. Fitzmaurice GM, Molenberghs G, Lipsitz SR. Regression models for longitudinal binary responses with informative drop-outs. Journal of the Royal Statistical Society, Series B 1995; 57:691-704. 
14. Troxel AB. A comparative analysis of quality of life data from a southwest oncology group randomized trial of advanced colorectal cancer. Statistics in Medicine 1998; 17:767-779.

15. O'Hara-Hines RJ, Hines WGS, Friesen TG. A comparison of two drop-out weighting schemes in the analysis of clustered data with categorical and continuous responses. Journal of Agricultural, Biological, and Environmental Statistics 1999; 4:203-216.

16. Miller ME, Ten Have TR, Reboussin BA, Lohman KK, Rejeski WJ. A marginal model for analyzing discrete outcomes from longitudinal surveys with outcomes subject to multiple cause non-response. Journal of the American Statistical Association 2001; 96:844-857.

17. Little RJA, Rubin DB. Statistical Analysis with Missing Data. Wiley: New York, 1987.

18. Troxel AB, Lipsitz SR, Brennan TA. Weighted estimating equations with nonignorably missing response data. Biometrics 1997; 53:857-869.

19. Rotnitzky A, Robins JM, Scharfstein DO. Semiparametric regression for repeated outcomes with nonignorable nonresponse. Journal of the American Statistical Association 1998; 93:1321-1339.

20. McCullagh P, Nelder JA. Generalized Linear Models. 2nd edn. Chapman and Hall: London, 1989.

21. Mancl LA, DeRouen TA. A covariance estimator for GEE with improved small-sample properties. Biometrics 2001; 57:126-134.

22. Robins JM, Rotnitzky A. Semiparametric efficiency in multivariate regression models with missing data. Journal of the American Statistical Association 1995; 90:106-121. 